\title{
Quantitative variation of secondary metabolites in the sea hare Aplysia parvula and its host plant, Delisea pulchra
}

\author{
Rocky de Nys ${ }^{1, *}$, Peter D. Steinberg ${ }^{1}$, Cary N. Rogers ${ }^{1}$, Timothy S. Charlton ${ }^{2}$, \\ Mark W. Duncan ${ }^{2}$
}

${ }^{1}$ School of Biological Science, ${ }^{2}$ Biomedical Mass Spectrometry Unit, University of New South Wales, Sydney 2052, Australia

\begin{abstract}
We measured quantitative variation of structurally similar halogenated furanones in the sea hare Aplysia parvula (Opisthobranchia; Anaspidea) and in its host alga Delisea pulchra (Rhodophyta; Bonnemaisonales). Mean total levels of furanones from $D$. pulchra in $A$. parvula were $13.3 \%$ of the dry weight of the sea hares, with one metabolite comprising on average $86 \%$ of the total metabolite load of the sea hares. Levels of furanones in the sea hares were highest in the digestive gland but were also found in other tissues, including the skin in at least $\mathrm{mg} \mathrm{g}^{-1}$ (dry wt) levels. Metabolite levels in the skin of the sea hares did not differ from those in D. pulchra (typically between 5 and $10 \mathrm{mg} \mathrm{g}^{-1}$ dry wt). Variation of metabolites in $D$. pulchra on the scale of both meters and kilometers was low and only minor variation in levels of individual metabolites was observed. There was significant variation in levels of metabolites within plants, with concentrations generally higher at the distal end of the thallus. The large differences in metabolite concentrations on a scale of millimetres found in some other red algae were not observed in $D$. pulchra. Metabolites occurred in significantly different relative amounts in $A$. parvula versus $D$. pulchra, with concentrations of individual metabolites in $A$. parvula ranging between 0 and 83 times the concentrations found in host algae. These results show that the sea hares differentially bioaccumulate algal metabolites. However, only 1 metabolite was enhanced in concentration in the sea hares relative to the alga. This metabolite was the most abundant compound in the animals, and has been previously shown to be effective as a predator deterrent. A second metabolite, which was not effective as a predator deterrent in $A$. parvula, decreased in relative concentration in the animals. In contrast to recent suggestions in the literature for sequestered algal metabolites in sea hares, our results indicate that the distribution and level of $D$. pulchra metabolites in $A$. parvula are consistent with a role as acquired chemical defences against predators.
\end{abstract}

KEY WORDS: Secondary metabolites - Aplysia parvula $\cdot$ Sequestered defences $\cdot$ Bioaccumulation $\cdot$ Red algae - Delisea pulchra

\section{INTRODUCTION}

Both terrestrial and marine organisms sequester secondary metabolites from their plant or animal prey, and in some cases utilise these compounds as defences against their own predators (reviewed by Faulkner 1992, Rowell-Rahier \& Pasteels 1992). In the marine environment sequestering of secondary metabolites is probably most common in the opisthobranch molluscs

\footnotetext{
•E-mail: r.denys@unsw.edu.au
}

(Mollusca; Opisthobranchia). Both the herbivorous sea hares (Opisthobranchia; Anaspidea) and ascoglossans (Ascoglossa), and the carnivorous nudibranchs (Nudibranchia) sequester defensive secondary metabolites from their algal (Paul \& van Alstyne 1988a, Paul \& Pennings 1991) or animal diets (Thompson et al. 1982 , Pawlik et al. 1988, Bobzin \& Faulkner 1989, Paul et al. 1990, Cronin et al. 1995).

Sequestered secondary metabolites in ascoglossans and nudibranchs deter potential predators of these animals (Pawlik et al. 1988, Hay et al. 1990, Paul et al. 1990, Cronin et al. 1995), and the pattern of seques- 
tration and presentation of these metabolites is consistent with a defensive role. The metabolites are typically stored or located in tissues which are most frequently exposed to predation such as cerata (Thompson et al. 1982, Pawlik et al. 1988, Di Marzo et al. 1993), and are also present in egg masses and surface mucous secretions (Roesener \& Scheuer 1986. Paul \& van Alstyne 1988a, Di Marzo et al. 1993). Some ascoglossans and nudibranchs also chemically modify sequestered metabolites to enhance their activity as feeding deterrents (Kernan \& Faulkner 1987, Paul \& van Alstyne 1988a), and selective accumulation of ingested metabolites may also occur (Thompson et al. 1982). De novo synthesis of deterrent compounds (Ireland \& Scheuer 1979, Vardaro et al. 1991) also occurs in these groups.

Sea hares in the order Anaspidea sequester secondary metabolites from chemically rich marine algae - particularly the red algal genera Plocamium and Laurencia, the brown algal family Dictyotaceae, and cyanobacteria (Paul \& Pennings 1991, Faulkner 1992). In contrast to the ascoglossans and nudibranchs, the evidence that sea hares sequester algal metabolites primarily for defensive purposes is equivocal. Sequestration of secondary metabolites by some sea hares is non-specific (Pennings \& Paul 1993a), with the animals readily acquiring metabolites from both dietary and non-dietary algae, and non-dietary sponges (Pennings \& Paul 1993a), Sea hares chemically modify some algal metabolites (Stallard \& Faulkner 1974, Paul \& Pennings 1991), but such chemical conversions do not appear to enhance the feeding deterrent properties of these metabolites (Paul \& Pennings 1991). In addition, the results of field assays for deterrence of predators by compounds isolated from sea hares are ambiguous, with a defensive or deterrent role demonstrated for some diet-derived metabolites (Paul et al. 1988, Paul \& Pennings 1991), but not others (Hay et al. 1987, 1988a, Paul et al. 1988).

Quantitative measurements of sequestered sea hare metabolites have also raised doubts about their defensive role. In particular, high concentrations of sequestered metabolites in sea hares are often not optimally located for defence. The highest concentrations of metabolites are usually found in the digestive gland, which is only accessible to predators following the death of the sea hare. Levels in tissues typically exposed to predators - skin, ink and eggs - are usually minimal or even undetectable (Faulkner 1992, Pennings \& Paul 1993b). In fact, the quantitative distribution of compounds in sea hares suggests that bioaccumulation may simply be a secondary consequence of the detoxification of ingested deleterious compounds.
This suggestion challenges the prevailing assumption that sequestered metabolites in sea hares are primarily used as a defense against predators (Faulkner 1992). However, with a few exceptions (Paul \& Pennings 1991, Pennings \& Paul 1993b), there is little quantitative evidence available on: (1) the distribution and abundance of different sequestered metabolites in sea hares; (2) the relationship between sequestered metabolites and the abundance of different metabolites in host plants; and (3) how variation in metabolite concentration in different body parts of sea hares relates to effective concentrations of these metabolites against relevant predators.

This lack of information on quantitative variation in metabolites for sea hares mirrors a similar paucity of information on quantitative variation in metabolites in algae. Most descriptions of variation in algal secondary metabolites are for brown algal phlorotannins (Ragan \& Glombitza 1986, Steinberg 1992, Targett et al. 1992) which are not structurally characterized and are measured as a group of compounds. Quantitative spatial and temporal variation in individual metabolites is only known for a few species of marine algae (e.g. Paul \& Fenical 1987, Hay et al. 1988b, Carlson et al. 1989, Meyer \& Paul 1992, Cronin \& Hay 1995).

In order to address the role(s) of sequestered secondary metabolites in sea hares, and to understand how variation in metabolites in their host plants affects bioaccumulation, a much fuller description of quantitative variation of metabolites within the animals, and within their host plants, is needed. In this study we describe quantitative variation in a suite of closely related secondary metabolites in the sea hare Aplysia parvula and its host alga, Delisea pulchra. In particular, we ask: (1) Are levels of metabolites and their distribution in A. parvula consistent with a defensive role for these metabolites? (2) How do D. pulchra metabolites vary among individual plants and within the thallus? And (3) is there evidence for differential bioaccumulation of compounds from $D$. pulchra by A. parvula?

\section{MATERIALS AND METHODS}

Study organisms. Delisea pulchra (Greville) Montagne (Bonnemaisonales, Rhodophyta) is a common foliose red alga found on sublittoral rocky reefs in the Sydney, New South Wales, region and elsewhere in southeastern Australia. The genus Delisea produces a variety of unique halogenated secondary metabolites (Pettus et al. 1977, Rose et al. 1977. McCombs et al. 1988), with D. pulchra in southeastern Australia producing a range of halogenated enones and furanones (Kazlauskas et al. 1977, de Nys et al. 1992, 1993). D. pulchra appears to be chemically well defended; it is a 
very low preference alga for several generalist herbivores from the Sydney region (Steinberg \& van Altena 1992), and produces metabolites which inhibit the settlement and growth of fouling organisms and marine bacteria (de Nys et al. 1995).

The sea hare Aplysia parvula is a cosmopolitan species abundant in the Sydney region from September to March (Rogers et al. 1995). As is the case elsewhere in the world, $A$. parvula near Sydney is a relatively specialized feeder and primarily occurs on, and consumes, the chemically rich red algae Delisea pulchra, Laurencia obtusa and L. rigida (Rogers et al. 1995).

Sample extraction. With the exception of the selection of samples to analyze (see below), quantitative variation in metabolites in both Delisea pulchra and Aplysia parvula was measured by similar extraction and analytical procedures. D. pulchra metabolites were analysed from samples of freeze dried algae (400 to $600 \mathrm{mg}$ ) or freeze dried A. parvula (200 to $750 \mathrm{mg}$ ). Preliminary studies established dichloromethane to be the solvent of choice for extraction of the metabolites from both sample types. All samples were exhaustively extracted by 5 sequential extractions in dichloromethane (i.e. initial extraction volume was $8 \mathrm{ml}$, followed by $4 \times 4 \mathrm{ml}$. In preliminary analyses, no metabolites were detected by the gas chromatography-mass spectrometry ( $\mathrm{gc}$-ms) procedures described below after the fourth extraction. The 5 extracts were combined, filtered (PTFE $0.5 \mu \mathrm{m}$ ), taken to dryness and the weight of crude extract determined. The extracts were then dissolved in ethyl acetate (EtOAc) containing 2-furoyl chloride as an internal standard at a concentration of $50 \mu \mathrm{g} \mathrm{ml}^{-1}$ (Sigma Chemical Co.). Samples for gc-ms were made up to a concentration of $1 \mathrm{ml}$ of EtOAc (+ internal standard) for each mg of crude extract (1 $\mathrm{mg} \mathrm{ml}^{-1}$ ).

Reference compounds. Standards used in the gc-ms analyses (metabolites 1 to 5 ; see Fig. 1) were isolated from a dichloromethane extract of freeze dried Delisea pulchra. Metabolites were isolated by vacuum liquid chromatography followed by high performance liquid chromatography (de Nys et al. 1993). All metabolites were identified by comparison of ${ }^{1} \mathrm{H}$ and ${ }^{13} \mathrm{C}$ NMR (nuclear magnetic resonance) data with that of published data (de Nys et al. 1993).

Gas chromatography-mass spectrometry. Gas chromatography was performed using a Hewlett Packard (HP) 5980 series II gas chromatograph (GC) and a polyimide-coated fused-silica capillary column (BP1, $50 \mathrm{~m}$ length, $0.22 \mathrm{~mm}$ i.d., $0.25 \mu \mathrm{m}$ dimethyl siloxane stationary phase; SGE Pty Ltd). All injections were performed in the splitless mode with an inlet pressure of $170 \mathrm{kPa}$. The injection port was held at $250^{\circ} \mathrm{C}$ and the interface at $300^{\circ} \mathrm{C}$. The $\mathrm{GC}$ was held at $50^{\circ} \mathrm{C}$ for $1.5 \mathrm{~min}$ and ramped at $20^{\circ} \mathrm{C} \mathrm{min}^{-1}$ to $300^{\circ} \mathrm{C}$ (and held there for $10 \mathrm{~min}$. Helium was used as the carrier gas. The mass spectrometry was performed on 2 separate systems, a HP 5971A, and a HP5972 Mass Selective Detector (MSD). Ions characteristic of the internal standard and 10 metabolites (numbered 1 to 10) were monitored in the selected ion monitoring mode (SIM) (Fig. 1). The E-isomers of metabolites 2 to 4 (Kazlauskas et al. 1977) were also detected as minor components in the crude extract. The 5 most abundant secondary metabolites ( 1 to 5) were quantitatively analysed using purified standards.

Quantification was performed by measuring peak areas for each compound and the internal standard. The ratio of peak areas (compound/internal standard) was calculated for each metabolite ( 1 to 5 ) and converted to concentration by reference to standard curves.

Selected samples were also analysed by gc-ms in the scan mode $(\mathrm{m} / \mathrm{z} 50$ to 650 ). Mass spectra were compared with those of reference samples previously isolated from Delisea pulchra (de Nys et al. 1992, 1993).

Bioaccumulation of Delisea pulchra metabolites by Aplysia parvula. Levels of metabolites in A. parvula collected from $D$. pulchra ( $\mathrm{n}=12$ host plants) at Bass and Flinder's Point, Cronulla, New South Wales $\left(34^{\circ}\right.$ $00^{\prime} \mathrm{S}, 151^{\circ} 14^{\prime} \mathrm{E}$ ) were measured by gc-ms. A. parvula ( $\mathrm{n}=23$ ) were removed from the plants, weighed, frozen, freeze dried and reweighed prior to chemical analysis for secondary metabolites. Individual sea hares weighed between 60 and $640 \mathrm{mg}$ (wet mass).

Location of metabolites within Aplysia parvula. Variation in bioaccumulated metabolites among different body parts of A. parvula was measured from 7 sea hares collected from individual Delisea pulchra plants at the Cape Banks Scientific Reserve, approximately $10 \mathrm{~km}$ north of Cronulla. The collected sea hares were

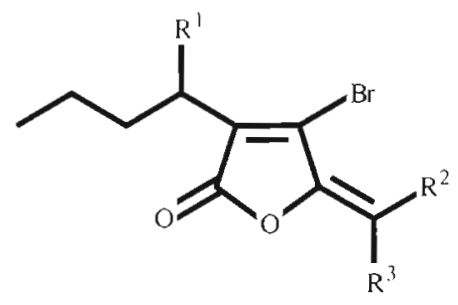

Fig. 1 Structure of Delisea pulchra metabolites (nos. 1 to 10) monitored by gas chromatography-mass spectrometry

\begin{tabular}{l|lll} 
& $\mathrm{R}^{1}$ & $\mathrm{R}^{2}$ & $\mathrm{R}^{3}$ \\
\hline $\mathbf{1}$ & $\mathrm{H}$ & $\mathrm{Br}$ & $\mathrm{Br}$ \\
$\mathbf{2}$ & $\mathrm{H}$ & $\mathrm{H}$ & $\mathrm{Br}$ \\
$\mathbf{3}$ & $\mathrm{OAc}$ & $\mathrm{H}$ & $\mathrm{Br}$ \\
$\mathbf{4}$ & $\mathrm{OH}$ & $\mathrm{H}$ & $\mathrm{Br}$ \\
$\mathbf{5}$ & $\mathrm{OAc}$ & $\mathrm{H}$ & $\mathrm{I}$ \\
$\mathbf{6}$ & $\mathrm{OAc}$ & $\mathrm{Br}$ & $\mathrm{Br}$ \\
$\mathbf{7}$ & $\mathrm{OH}$ & $\mathrm{Br}$ & $\mathrm{Br}$ \\
$\mathbf{9}$ & $\mathrm{OH}$ & $\mathrm{H}$ & $\mathrm{Cl}$ \\
$\mathbf{1 0}$ & $\mathrm{OH}$ & $\mathrm{H}$ & $\mathrm{I}$
\end{tabular}


frozen and subsequently dissected under binocular microscope into 7 main body parts, the digestive gland $(\mathrm{dg})$, the anterior mantle gland (amg), the opaline gland (opg), the purple gland including ink (pg), the oil (oil), the skin (skin), and a collection of remaining tissue (rest) (e.g. oesophagus, crop). The dissected tissues from each sea hare $(n=7)$ were weighed, refrozen and freeze dried. The freeze dried tissue was then reweighed, extracted as for the whole animal samples, and the extracts analysed by gc-ms.

Measurement of metabolites in Delisea pulchra. Variation of metabolites in D. pulchra was also measured. This was done both because of intrinsic interest in patterns of variation in algal metabolites, and because the feeding history of the Aplysia parvula analysed here was not known. In order to examine whether different $D$. pulchra metabolites were differentially bioaccumulated by $A$. parvula, it was necessary to document variation in metabolites among and within potential host plants, so that we could determine the possible mixtures of metabolites the sea hares may have been feeding on. Two sources of variation in metabolites in $D$. pulchra were measured - spatial variation among individual plants (since animals may move between plants), and variation within a plant (since A. parvula may only feed on particular parts of a thallus). Temporal variation in $D$. pulchra metabolites will be described in a separate report.

Interplant variation in the secondary chemistry of Delisea pulchra was measured by comparing the secondary metabolite content of whole plants from Bass and Flinder's Point, Cronulla, on which Aplysia parvula were found (host plants) with (1) the secondary metabolite content of nearby (within meters) non-host plants and (2) the secondary metabolite content of $D$. pulchra collected at Cape Banks. Intraplant variation was measured in 2 ways. Firstly, host (A parvula present) and non-host (A. parvula absent) plants from Cronulla ( $n=12$ for each) from a depth of 2 to $3 \mathrm{~m}$ were collected intact including the holdfast. Aplysia parvula were removed from the plants (see previous section), the plants weighed, divided into thirds (top, middle and bottom) laterally, and each section reweighed. The samples were then frozen, freeze dried, reweighed prior to extraction, and analysed by gc-ms.

In order to assess smaller scale variation of secondary metabolites within a plant, in particular at the apical meristem, a second analysis of intraplant variation. was measured in plants collected from Cape Banks. Plants without Aplysia parvula $(\mathrm{n}=10)$ from a depth of 2 to 3 m were collected intact including holdfast. The plants were weighed and divided laterally into 5 sections. The apical portions of thalli (1 to $5 \mathrm{~mm}$ in length; part $A$ ) and adjacent sub-apical portions (15 to $20 \mathrm{~mm}$ in length; part B) were removed by scalpel. The remaining part of the plant was divided into 3 equal sections (parts $C$ to $E$ ). The plants were processed, extracted and analysed for secondary metabolite content as previously described.

Statistical analyses. Most comparisons of variation in metabolites were done using analysis of variance followed by Tukey's multiple range test (where appropriate). Multiple range tests for samples with unequal samples sizes and equal variances were carried out using the Kramer-modified Tukey's test (Day \& Quinn 1989). Homogeneity of variances was tested with Cochran's test. Most data were analysed as percentages or proportions (e.g. $\mathrm{mg}$ of compounds $\mathrm{g}^{-1} \mathrm{dry}$ mass; see Fig. 2) after transformation by arcsin $\downarrow p$. We note that (also see Pennings \& Paul 1993b) there is the possibility that variation in levels of a metabolite among parts of an individual animal or plant, or among different furanones within a single individual, may not be independent of each other In an attempt to partition the overall effect of variation among plants or animals from the variation among individual parts (of animals) or sections (of plants), analyses which included Position or Part as a factor were done as blocked analyses (Sokal \& Rohlf 1981), with 'Plant' or 'Source' (where animals and plants were combined in a single analysis) as random blocked factor(s). Other factors were treated as fixed.

\section{RESULTS}

\section{Bioaccumulation of Delisea pulchra metabolites by Aplysia parvula}

Four of the five metabolites detected in Delisea pulchra (nos. 1 to 4 ; Fig. 1) were also detected in Aplysia parvula (Fig. 2). These 4 metabolites were biomagnified in the sea hares, with mean concentrations $\left(\mathrm{mg} \mathrm{g}^{-1}\right.$ dry wt) of metabolites 1 to 4 in A. parvula between 8 (for metabolite 4) and 83 (for metabolite 3) times greater than the mean concentrations in host plants (Fig, 2). Metabolites 1 to 3 were detected in all sea hares analysed. Metabolite 4 was only detected in 10 of the 23 sea hares, and metabolite 5 was not detected in any of them. Metabolite 3 was by far the most abundant, accounting for a mean of $86 \%$ of the total metabolite content of the sea hares (range 78 to $93 \%$ ). Metabolite 3 was present in significantly greater quantities than all other metabolites in the sea hares, and levels of metabolite 1 were significantly higher than those of metabolite 4 (1-factor ANOVA followed by Tukey's, $\alpha=0.05 ;$ Fig. 2). The average total concentration of metabolites in A. parvula was $13.3 \%$ of dry mass, with concentrations in a few individuals exceeding $30 \%$ of dry mass. 


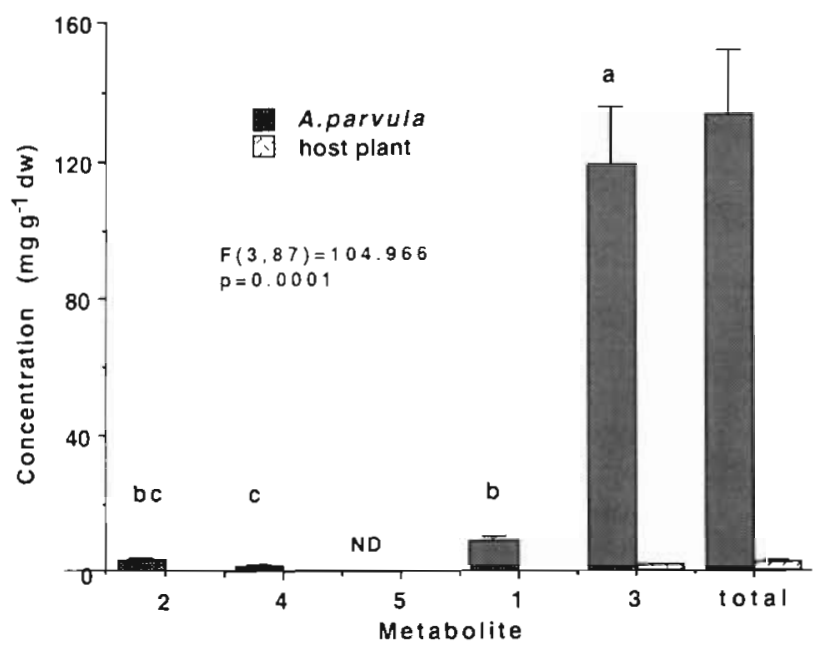

Fig. 2. Concentration of metabolites 1 to 5 in Aplysia parvula and host Delisea pulchra plants. Mean $+\mathrm{SE}, \mathrm{n}=23$ for $A$. parvula, $\mathrm{n}=12$ for $D$. pulchra. Compounds with the same letters above them $(a, b, c)$ do not differ at $\alpha=0.05$ (Tukey's test). ND: not detected in A. parvula

\section{Location of metabolites within Aplysia parvula}

As in previous studies of opisthobranch molluscs, the concentration of sequestered metabolites in Aplysia parvula differed strikingly among different body parts (Fig. 3A-D). Levels of total metabolites (Fig. 3A) and individual metabolites 2 to 3 (Fig. $3 \mathrm{~B}-\mathrm{C}$ ) were significantly higher in the digestive gland than in any other body part (2-factor ANOVA without replication, with Animals as the blocked factor, followed by Tukey's, $\alpha=$ $0.05)$. Levels of metabolite 1 in the digestive gland were significantly higher than those in several other body parts (Fig. 3D). Metabolite 4 was not detected in any samples and metabolite 5 was only detected in 3 samples at trace levels $\left(<1 \mathrm{mg} \mathrm{g}^{-1}\right.$ dry wt). The skin, which is the part of the animal which predators would first contact, contained low levels of metabolites $\left(<5 \mathrm{mg} \mathrm{g}^{-1}\right.$ dry wt), but these concentrations did not differ significantly from those in several other parts of the body except for the digestive gland. Furthermore there was no significant difference between levels of individual (metabolites 1,2 and 3) or total metabolites in the skin and those in the host plants (Fig. 3A-D).

\section{Variation of metabolites among plants}

While there were large differences in the concentrations of different metabolites in the plants (Fig. 4), variation of metabolites between individual plants was relatively low. There was no difference in total metabolite loads between host or non-host Delisea pulchra at
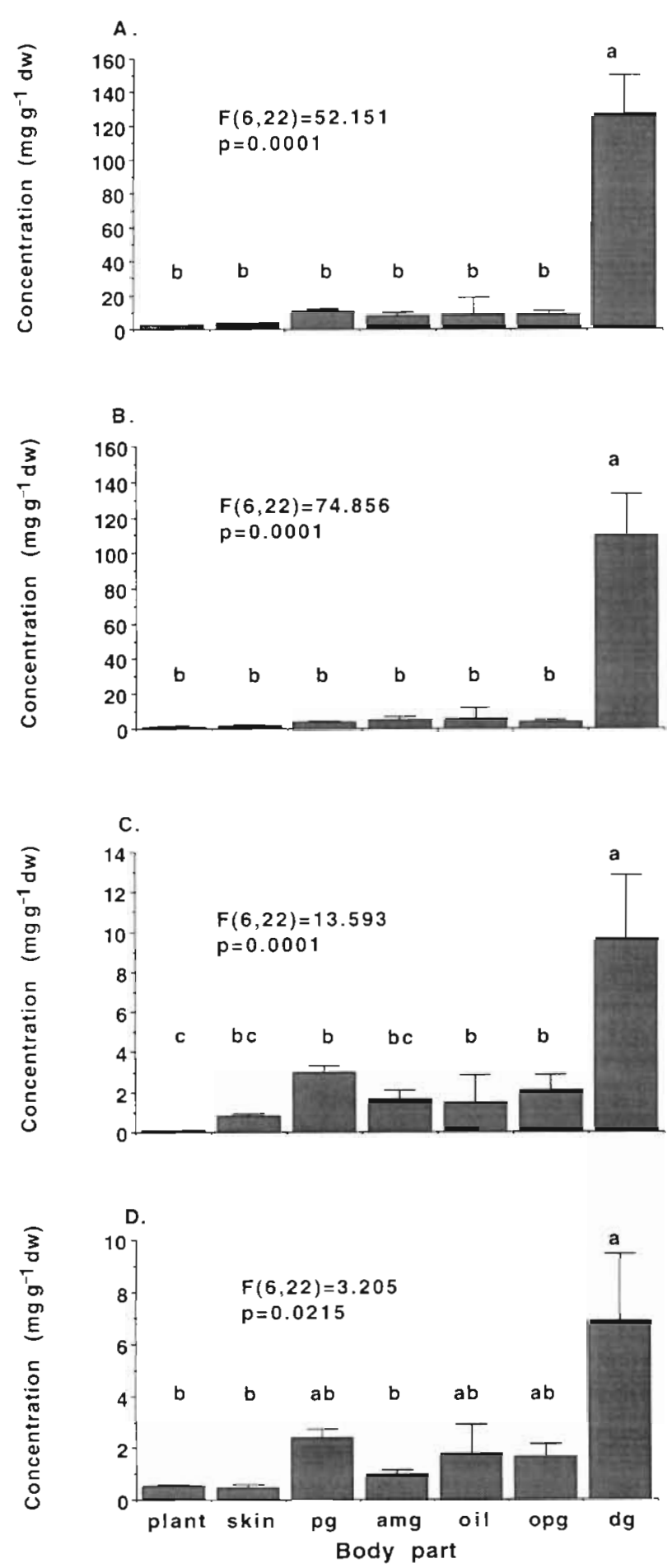

Fig. 3. Concentration of (A) total metabolites, (B) metabolite 3, (C) metabolite 2, and (D) metabolite 1 in Delisea pulchra (plant), and the skin, purple gland (pg), anterior mantle gland (amg), oil, opaline gland (opg), and digestive gland (dg) of Aplysia parvula. Means $+\mathrm{SE}, \mathrm{n}=7$ for A. parvula, $\mathrm{n}=29$ for $D$. pulchra. Analyses are 2-factor ANOVAs (blocked by Source of tissue) followed by Tukey's. Body parts sharing the same letters above them $(a, b, c)$ do not differ at $\alpha=0.05$ 


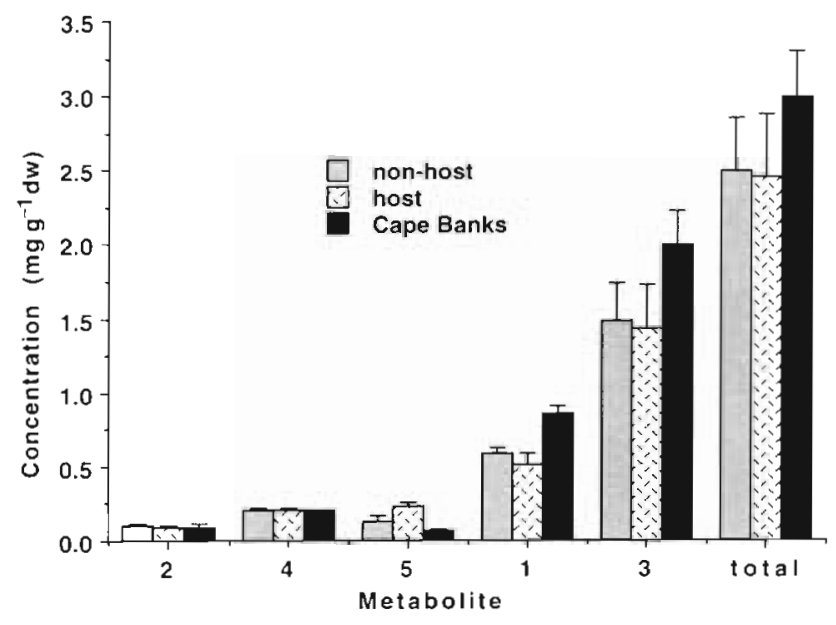

Fig. 4. Concentration of metabolites 1 to 5 and total metabolites in host and non-host Delisea pulchra collected from Cronulla and non-host $D$. pulchra collected from Cape Banks. Means $+S E, n=12$ for plants from Cronulla, $n=29$ for plants from Cape Banks

Cronulla, and D. pulchra from Cape Banks (Fig. 4, Table 1a). When concentrations of individual metabolites were analysed (Table $1 \mathrm{~b}$ ), there was again no overall effect of the source of the thallus (where the plant was collected), although specific metabolites did differ in some instances. Metabolites 1 and 3, which were highest in plants from all 3 sources, were found in higher concentrations in plants from Cape Banks than in those from Cronulla (Tukey's test, $\alpha=0.05$ ). Levels of metabolite 5 were significantly higher in host plants from Cronulla than in non-host plants and plants from Cape Banks (Fig. 4). There was however no significant difference in concentrations of metabolites 2 and 4 between host and non-host plants at Cronulla and those from Cape Banks (Table 1b, Tukey's test).

Table 1 Delisea pulchra. (a) One-factor analysis of variance for arcsin vp transformed total concentration of metabolites in host, non-host plants from Cronulla and plants from Cape Banks. (b) Two-factor analysis of vanance for arcsin vp transformed concentration of metabolites (factor A) in host, nonhost plants from Cronulla and plants from Cape Banks (factor B)

\begin{tabular}{|c|c|c|c|c|}
\hline Factor & df & MS & $F$ & $p$ \\
\hline \multicolumn{5}{|c|}{ (a) One-factor ANOVA } \\
\hline Source & 2 & 1.073 & 1.637 & 0.2029 \\
\hline Error & 62 & 0.656 & & \\
\hline \multicolumn{5}{|c|}{ (b) Two-factor ANOVA } \\
\hline Metabolites (A) & 4 & 26.219 & 156.282 & 0.0001 \\
\hline Source (B) & 2 & 0.305 & 1.816 & 0.1644 \\
\hline$A \times B$ & 8 & 0.631 & 3.76 & 0.0003 \\
\hline Error & 310 & 0.168 & & \\
\hline
\end{tabular}

\section{Variation of metabolites within plants}

There was no difference in the pattern of metabolite change between host and non-host plants from Cronulla (Fig. 5, Table 2a, b). In general, metabolites within plants consistently decreased in concentration from the distal tip to the base of the thallus (Figs. 5A, B, Table 2a, b). However, the magnitude of the decrease varied among metabolites (e.g. significant Metabolite $\times$ Position interaction term in Table $2 b$ ), with significant changes in concentration only occurring for metabolites 3 and 4 (Tukey's test, $\alpha=0.05$ ).

Delisea pulchra analysed for smaller scale variation of metabolites within plants at Cape Banks (Fig. 6, Table $3 a, b)$ exhibited a very similar pattern of variation to those from Cronulla. The most distal sections, comprised of the apical meristematic tips, were again richest in metabolites. Small scale variation (the apical and subapical sections were only 2 to $6 \mathrm{~mm}$ in size) of individual metabolites followed a similar pattern to variation among larger sections, with apical tips higher in metabolites 2 to 4 than more basal sections (Tukey's test, $\alpha=0.05$ ).
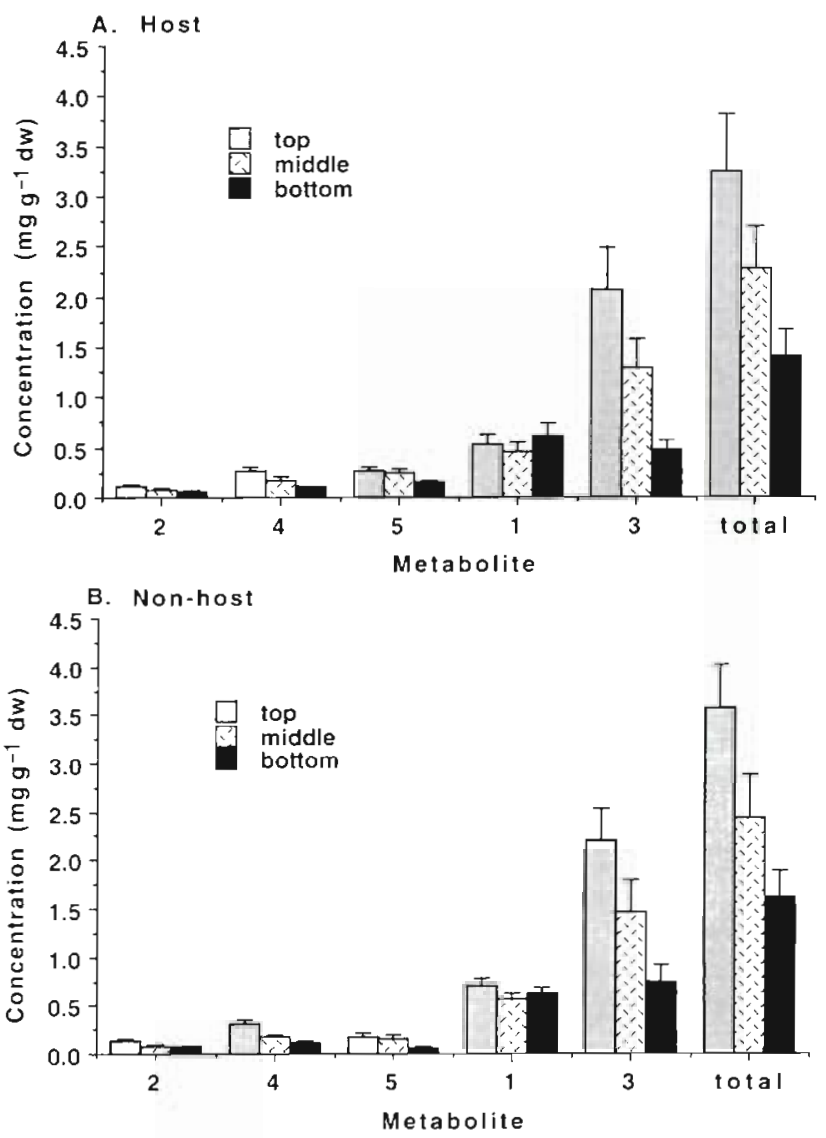

Fig. 5. Concentration of metabolites 1 to 5 and total metabolite in top, middle and bottom portions of (A) host and (B) non-host Delisea pulchra from Cronulla. Means $+\mathrm{SE}, \mathrm{n}=12$ 
Table 2. Delisea pulchra. (a) Three-factor analysis of variance for arcsin $\vee p$ transformed total concentration of metabolites in top, middle and bottom positions (factor B) of host and nonhost plants (factor A). (b) Four-factor analysis of variance for arcsin $\vee p$ transformed concentration of individual metabolites (factor $B$ ) in top, middle and bottom plant parts (factor C) from host and non-host plants from Cronulla (factor A)

\begin{tabular}{|lcccc|}
\hline Factor & df & MS & $F$ & $p$ \\
\hline (a) Three-factor ANOVA & & & \\
Block (= Plant) & 15 & 1.8442 & 3.8688 & 0.0001 \\
Source (A) & 1 & 1.4381 & 3.0167 & 0.0871 \\
Position (B) & 2 & 6.041 & 12.673 & 0.0001 \\
A $\times$ B & 2 & 0.3667 & 0.7693 & 0.4674 \\
Error & 66 & 0.47669 & & \\
& & & & \\
(b) Four-factor ANOVA & & & \\
Block (= Plant) & 15 & 1.2761 & 9.140 & 0.0001 \\
Source (A) & 1 & 0.2759 & 1.977 & 0.1605 \\
Metabolites (B) & 4 & 27.944 & 200.16 & 0.0001 \\
A $\times$ B & 4 & 0.7994 & 5.719 & 0.0002 \\
Position (C) & 2 & 4.2042 & 30.115 & 0.0001 \\
A $\times$ C & 2 & 0.2021 & 1.448 & 0.2363 \\
B $\times$ C & 8 & 1.3572 & 9.721 & 0.0001 \\
A $\times$ B $\times$ C & 8 & 0.076 & 0.544 & 0.8227 \\
Error & 405 & 1.838 & & \\
\hline
\end{tabular}

\section{Differential biomagnification of metabolites by Aplysia parvula}

In order to assess whether Aplysia parvula differentially bioaccumulated Delisea pulchra metabolites, the ratios of individual compounds to total metabolite loads were compared for $A$. parvula, the top, middle, bottom sections of plants from Cronulla, and the whole thallus of these plants. If A. parvula differentially accumulates metabolites from $D$. pulchra, then the ratios in

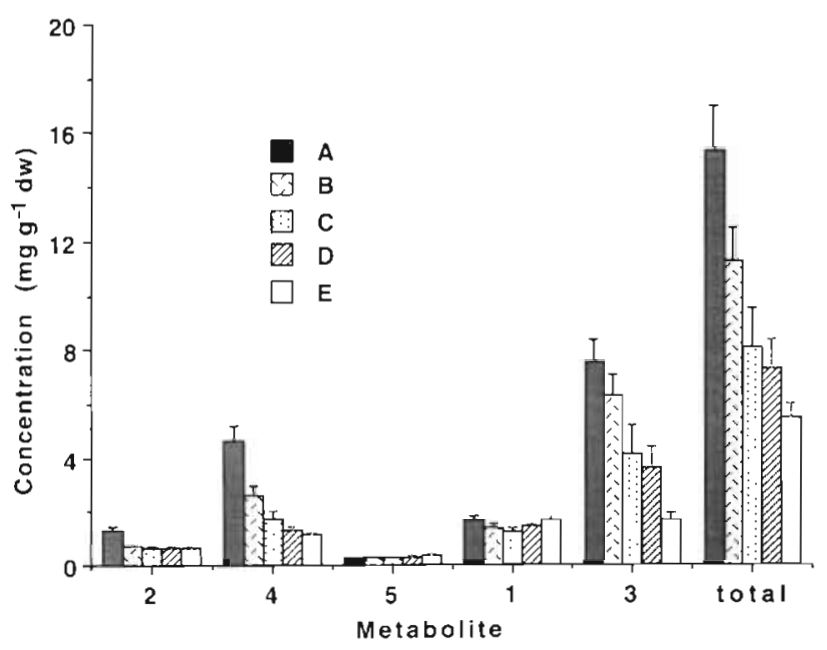

Fig. 6. Concentration of metabolites 1 to 5 and total metabolites in portions of Delisea pulchra from the apices $(A)$ to the base (E). Plants were collected at Cape Banks. Means $+\mathrm{SE}, \mathrm{n}=10$
Table 3. Delisea pulchra. (a) Two-factor analysis of variance for arcsin $\vee p$ transformed concentration of total metabolites in positions $A$ to $E$ of plants from Cape Banks. (b) Three-factor analysis of variance for arcsin $v p$ transformed concentration of metabolites in positions A to E of plants from Cape Banks

\begin{tabular}{|lrrrc|}
\hline Factor & df & MS & $F$ & $\mathrm{p}$ \\
\hline (a) Two-factor ANOVA & & & \\
Block (= Plant) & 9 & 3.13216 & 5.2418 & 0.0001 \\
Position & 4 & 12.3147 & 20.609 & 0.0001 \\
Error & 36 & 0.59753 & & \\
& & & & \\
(b) Three-factor ANOVA & & & \\
Block (= Plant) & 9 & 2.4705 & 7.8299 & 0.0001 \\
Metabolites (A) & 4 & 31.7114 & 100.5048 & 0.0001 \\
Position (B) & 4 & 15.1360 & 47.9714 & 0.0001 \\
A $\times$ B & 16 & 3.2730 & 10.3734 & 0.0001 \\
Error & 216 & 0.31552 & & \\
\hline
\end{tabular}

the animals should differ significantly from those in the algae. This hypothesis was assessed using 1-factor ANOVAs (excluding the whole thallus) for each metabolite because such ratios are not independent among metabolites from individual plants. Because patterns of variation in host versus non-host plants from Cronulla were essentially identical, data for the 2 groups of plants were combined for this analysis.

Ratios of individual compounds to total metabolite load differed signficantly among different tissues for all compounds except metabolite 2 (Fig. 7A-E). The most abundant metabolite, 3, occurred in a significantly higher proportion (Tukey's test, $\alpha=0.01$ ) in Aplysia parvula $($ mean $=87.0 \%$ ) than in the algal tissue (mean across all tissue sources $=49.5 \%$ ) (Fig. $7 \mathrm{~A})$. The ratio of metabolites 1 and 4 was significantly lower in $A$. parvula than in plant parts (Fig. 7B to C) (Tukey's test, $\alpha$ $=0.01$ ) and metabolite 5 was not detected in A. parvula

To determine whether metabolites are differentially bioaccumulated at the surface of the sea hares, where they are thought to be most effective as predator deterrents, the ratios of metabolites were compared for the whole plants versus the skin and whole body (calculated from individual parts) of Aplysia parvula from Cape Banks (Fig. 8). The ratios differed significantly among source types for all metabolites except metabolite 5 (1-factor ANOVAs followed by Tukey's test) (Fig 8). Metabolite 3 occurred in a significantly higher proportion in whole $A$. parvula than in the skin of the animals or the whole plant, which were not significantly different from each other (Tukey's test, $\alpha=0.05$ ). The ratio of metabolite 2 was significantly higher in the skin than in whole animals or plants, while the ratio of metabolite 1 was significantly higher in whole plants than in animals but was not significantly different from the ratio in the skin (Fig. 8, Tukey's test, $\alpha=0.05$ ). Metabolite 4 was not detected in A. parvula samples. 

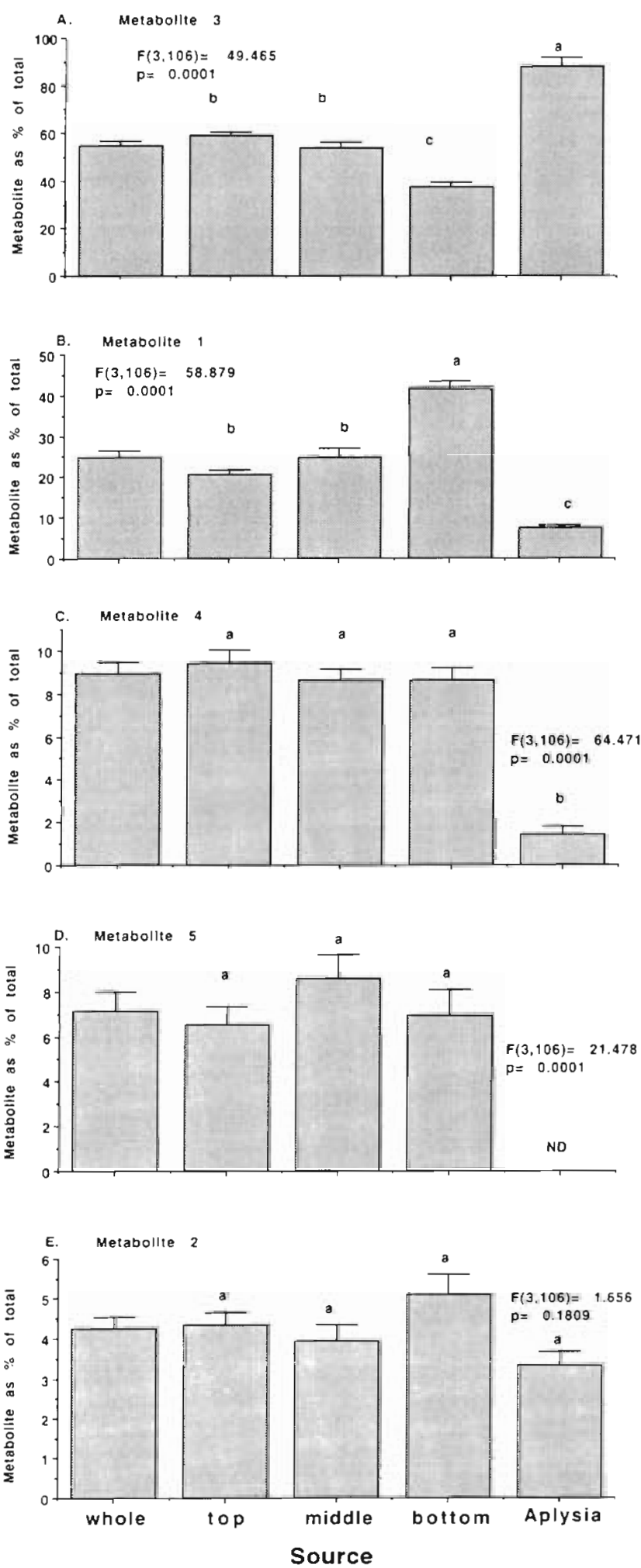

Fig. 7. Metabolites 1 to 5 as a percentage of total metabolites for the top, middle and bottom portions of Delisea pulchra $(\mathrm{n}=24)$. whole D. pulchra $(\mathrm{n}=24)$ and Aplysia parvula $(\mathrm{n}=23)$. Metabolites are presented from $(A)$ to $(E)$ in decreasing order of $a b$ solute abundance. Means + SE; ND: not detected. Metabolites with the same letter above them $(a, b, c)$ do not differ at $\alpha=0.05$

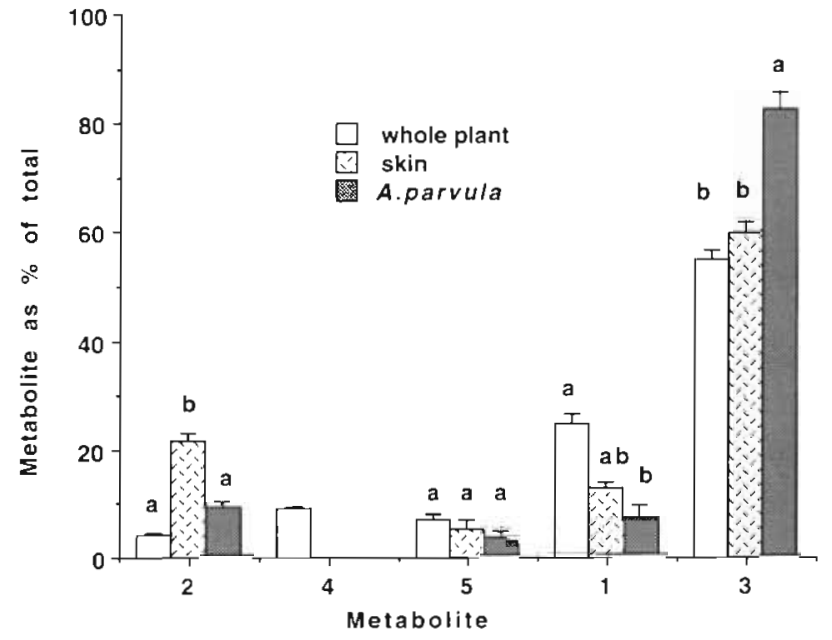

Fig. 8. Metabolites 1 to 5 as a percentage of total metabolites for whole Delisea pulchra $(\mathrm{n}=29)$, the skin of Aplysia parvula $(n=7)$, and whole A. parvula $(n=7)$. Means + SE. Compounds with the same letter above them $(a, b)$ do not differ at $\alpha=0.05$

\section{DISCUSSION}

\section{Variation in acquired seaweed metabolites in Aplysia parvula}

Like numerous other sea hares (reviewed in Carefoot 1987, Faulkner 1992), Aplysia parvula sequesters metabolites from its host algae, in this case Delisea pulchra. Metabolites are accumulated to high concentrations; on average 12 to $13 \%$ of the dry mass of the animals was comprised of $D$. pulchra metabolites, with levels in some animals exceeding $30 \%$ dry mass. These concentrations of metabolites are comparable to, or higher than, previously reported concentrations of sequestered algal metabolites in sea hares (Paul \& Pennings 1991, Pennings \& Paul 1993b) or ascoglossans (Paul \& van Alstyne 1988a), and dietary metabolites in nudibranches (Pawlik et al. 1988). The concentration of sequestered metabolites in the sea hares also varied significantly among different body parts, with very high levels in the digestive gland and relatively low levels in other body parts. This pattern is consistent with previous descriptions of qualitative (Winkler 1969) and quantitative (Pennings \& Paul $1993 b)$ variation in algal secondary metabolites in sea hares.

As discussed in the 'Introduction', this pattern - in which metabolites are concentrated in the digestive gland rather than in body parts such as the skin which are more exposed to predators - has raised doubts about the defensive role of sequestered algal metabolites in sea hares (Pennings \& Paul 1993b, 
Pennings 1994). For secondary metabolites to affect predators directly as feeding deterrents, they need to be present at the surface of the animal, or be able to be extruded rapidly to the surface before injury or death occurs (Brower et al. 1988). However, there are few descriptions of quantitative variation in metabolites in sea hares, and no examples of which we are aware where the full range of quantitative variation for different parts of the animals has been tested against predators in the field. Several studies have demonstrated that the skin of sea hares is distasteful to predators, but had no supporting chemical evidence (Ambrose et al. 1979, Pennings 1990, 1994). We also note that consumption of sea hares may result in subsequent learned aversion to the animals in some predators (Lindquist \& Hay 1995), in which case the concentrations in the skin may be sufficient to act as deterrents by functioning as signals to predators of the higher concentrations of compounds inside the animals. In general, while concentrations of metabolites in exterior body parts of Aplysia parvula are generally lower than in the digestive gland, these lower concentrations may still effectively deter predators, either directly, or indirectly as signals.

We do not yet know whether Delisea pulchra metabolites deter predators at the concentrations found in the skin. However, approximate whole body concentrations (12\% dry mass) of the most abundant $D$. pulchra metabolite in Aplysia parvula, metabolite 3 , deter feeding by predatory fish in the field (Rogers et al. 1995). Moreover, the concentrations of $D$. pulchra metabolites present in the skin of $A$. parvula are as high or higher than concentrations in the alga itself, and $D$. pulchra is strongly unpalatable to common generalist herbivores near Sydney (Steinberg \& van. Altena 1992). Crude extract of D. pulchra and selected metabolites deter feeding by large generalist herbivores (metabolites 1,2 and 3; de Nys 1992, de Nys et al. unpubl.) and amphipods (metabolites 2 and 3; de Nys et al. unpubl.) at natural levels. These compounds have also been found to be active in a range of biological assays at very low levels. They are antibacterial (Reichelt \& Borowitzka 1984, de Nys et al. 1995) and inhibit the settlement of barnacle larvae and algal spores at ppm levels or less (de Nys et al. 1995). More generally, the concentrations of metabolites found in the skin of A. parvula - typically 0.3 to $1.0 \%$ dry mass - are comparable to levels at which other algal metabolites deter a wide variety of marine herbivores (Hay et al. 1987, 1988a, Paul et al. 1988), although these concentrations may be less effective against marine predators which consume animal tissue that is higher in nutrient content than algae (Duffy \& Paul 1992).

\section{Differential accumulation of Delisea pulchra metabolites by Aplysia parvula}

Our results demonstrate the differential accumulation of Delisea pulchra metabolites. The ratios of several metabolites in the whole animals, in particular metabolites 3 and 4 , are significantly different from those of their host plants and from each other. One metabolite (5) which was present in all host plants was not found at detectable levels in the animals. Two of these metabolites have been tested for their effects against predators in the field (3,4; Rogers et al. 1995). Metabolite 3 deters predators at natural concentrations in the animal (Rogers et al. 1995) and its levels are enhanced in Aplysia parvula relative to D. pulchra. Metabolite 4 is not effective against predators in the field at 10 times natural concentrations, and is lower in $A$. parvula relative to $D$. pulchra. This is the expected pattern of bioaccumulation if deterrence of predators is an important role of these compounds.

The evidence for differential accumulation is not unequivocal because we do not know the feeding history of the sea hares sampled. However, the range of potential mixtures of metabolites that the sea hares might encounter has been documented by sampling different plants and parts of plants. There was no evidence that sea hares would encounter a substantially different mixture (or ratio) of compounds if they fed on non-host plants versus host plants, or on different parts of the plants. The pattern of sequestered metabolites may reflect the fact that a different mixture of metabolites was present in the plants prior to our sampling. However, in 18 months of seasonal sampling of Delisea pulchra metabolites at Cape Banks, ratios of metabolites were similar to those described here (de Nys et al. unpubl.). Cross sectional variation in metabolite concentrations (Tugwell \& Branch 1989) was not relevant here because Aplysia parvula consume entire sections of a thallus when feeding, rather than simply scraping off exterior layers.

We note that differential accumulation does not necessarily imply selective sequestration. Differential accumulation may be due to a number of processes, including differential uptake of metabolites, differential depuration, or interconversion of metabolites. Other opisthobranchs (ascoglossans and nudibranchs) that contain secondary metabolites in different ratios to their dietary source may either selectively bioaccumulate metabolites (Thompson et al. 1982) or chemically modify them (Kernan \& Faulkner 1987, Paul \& van Alstyne 1988a, Pawlik et al. 1988). Metabolites which are enhanced in the animals may act as more effective feeding deterrents than those which are not (Kernan \& Faulkner 1987). However, the sea hare species Stylocheilus longicauda and Dolabella auricularia 
convert the hydroxylated algal metabolite malyngamide $B$ to its acetylated analogue malyngamide $B$ acetate (Pennings \& Paul 1993b), which is a less effective feeding deterrent than malyngamide B. A similar chemical conversion may be occurring in Aplysia parvula based on a relative decrease of metabolite 4 (hydroxylated) and relative increase of metabolite 3 (acetylated). However, acetylated compounds per se do not accumulate in $A$. parvula, because the acetylated metabolite 5 was not detected in the animals but was present in host plants.

Although we have argued here that the levels and distribution of furanones in Aplysia parvula are consistent with a defensive role against predators, an alternative (and not mutually exclusive) possible function for these compounds is that they act as chemical camouflage for the animals. The colour of $A$. parvula on Delisea pulchra closely resembles that of the host plant and the levels and ratios of metabolites in the skin of $A$. parvula are similar to those in D. pulchra. Sequestering metabolites to mimic the chemical composition of a chemically defended alga may further decrease detection by predators. Although Pennings (1990) found no evidence for chemical crypsis in juvenile Aplysia californica, chemical camouflage due to acquired plant metabolites is known for other marine gastropods (Fishlyn \& Phillips 1980).

\section{Variation of secondary metabolites in marine algae}

A number of authors (Paul 1992, Steinberg 1992) have recently highlighted the need for a much fuller description of quantitative variation of secondary metabolites in marine algae. To date, quantitative descriptions of variation in algal metabolites have been largely restricted to studies on brown algal phlorotannins (Ragan \& Glombitza 1986, Steinberg 1992, Targett et al. 1992). However, this information is limited because these analyses are based on colorimetric techniques which measure phlorotannins as a group. That is, they provide no information on individual, structurally characterized metabolites.

Studies on quantitative variation of structurally characterized macroalgal secondary metabolites are remarkably limited in number, particularly for algal species which produce a complex mixture of metabolites. Variation in bromophenols in the red alga Neorhodomela larix has been described by Carlson et al. (1989) and Phillips \& Towers (1982). This work demonstrated that lanosol, the major metabolite in the plants, could vary by several orders of magnitude between adjacent portions of the thallus. Cronin \& Hay (1995) describe within-plant variation of secondary metabolites in the brown alga Dictyota ciliolata, with higher levels of some metabolites present in older, less palatable tissue than in apical meristems. Secondary metabolites in the green algal families Caulerpaceae and Udoteaceae show significant between- (Paul \& Fenical 1986, 1987 , Paul \& van Alstyne 1988b) and within-plant (Hay et al. 1988b, Paul \& van Alstyne 1988b, Meyer \& Paul 1992) spatial variation, both of which correlate with temporal or spatial variation in herbivory.

Quantitative variation of halogenated furanones in Delisea pulchra in our study was relatively low compared to the previous studies cited above, with most metabolites only differing by a factor of ca 2 to 3 among different parts of plants or different sites. The greatest variation we observed was between individual metabolites within a thallus, Metabolite 3 - the most abundant metabolite - occurred at up to 15-20 times the levels of metabolites 2 and 5. Other related metabolites in $D$. pulchra can occur at even lower concentrations (de Nys et al. 1993). Variation within plants was predictable, with most metabolites steadily decreasing in concentration from the distal tip to the base of the plant. There was no evidence for the kinds of microscale variation in metabolites observed for Neorhodomela larix (Carlson et al. 1989). Concentrations of metabolites were highest in the apical, meristematic tips of the algae, similar to the pattern of variation reported in Halimeda spp. (Hay et al. 1988b, Paul \& van Alstyne 1988b). Variation between plants at the scale of meters (host versus non-host plants) or kilometers (Cronulla versus Cape Banks) was low and not significant overall (Table 1), although in a few instances individual metabolites did differ among sites.

Acknowledgements. We thank D. van Dyke, H. Baillie and P. Harrison for their assistance in the field and laboratory, and A. G. B. Poore and J. Wright for comments on the manuscript. The research was supported by an ARC Programme Grant to P. D. Steinberg and an ARC Postdoctoral Fellowship to R. de Nys.

\section{LITERATURE CITED}

Ambrose HW, Givens RP. Chen R, Ambrose KP (1979) Distastefulness as a defense mechanism in Aplysia brasiliana (Mollusca: Gastropoda). Mar Behav Physiol 6:57-64

Bobzin SC, Faulkner DJ (1989) Diterpenes from the marine sponge Aplysilla polyrhaphis and the dorid nudibranch Chromodons norrist. J org Chem 54:3902-3907

Brower LP, Nelson CJ, Seiber JN, Fink LS, Bond C (1988) Exaptation as an alternative to coevolution in the cardenolide-based chemical defense of monarch butterflies (Danaus plexippus L.) against avian predators. In: Spencer KC (ed) Chemical mediation and coevolution. Academic Press, San Diego, p 447-476

Carefoot TH (1987) Aplysia: its biology and ecology. Oceanogr mar Biol A Rev 25:167-284

Carlson DJ, Lubchenco J, Sparrow MA, Trowbndge (I) (1989) Fine-scale variability of lanosol and its disultate ester in the temperate red alga Neorhodomela larix. J chem Ecol 15:1321-1333 
Cronin G, Hay ME (1995) Within-plant variation in seaweed chemical defences: optimal defence theory versus the growth-differentiation balance hypothesis. Oecologia (in press)

Cronin G. Hay ME, Fenical W, Lindquist N (1995) Distribution, density, and sequestration of host chemical defenses by the specialist nudibranch Tritonia hamnerorum found at high densities on the sea fan Gorgonia ventalina. Mar Ecol Prog Ser 119:177-189

Day RW, Quinn G P (1989) Comparısons of treatments after an analysis of variance in ecology. Ecol Monogr 56:345-363

de Nys R (1992) Natural products chemistry and chemical ecology of tropical marine algae. PhD thesis, James Cook Univ, Townsville

de Nys R, Coll JC, Bowden BF (1992) Delisea pulchra (cf. fimbriata) revisited. The structural determination of two new metabolites from the red alga Delisea pulchra. Aust J Chem 45:1625-1632

de Nys R, Steinberg PD, Willemsen P, Dworjanyn SA, Gabelish CL, King RJ (1995) Broad spectrum effects of secondary metabolites from the red alga Delisea pulchra in antifouling assays. Biofouling 8:259-271

de Nys R, Wright AD, Konig GM, Sticher O (1993) New halogenated furanones from the marine alga Delisea pulchra (cf. fimbriata). Tetrahedron 49:11213-11220

Di Marzo VD, Marin A, Vardaro RR, do Petrocellis L, Villani G. Cimino G (1993) Histological and biochemical bases of defense mechanisms in four species of Polybranchioidea ascoglossan molluscs. Mar Biol 117:367-380

Duffy JE, Paul VJ (1992) Prey nutritional quality and effectiveness of chemical defences against tropical reef fishes. Oecologia 90:333-339

Faulkner DJ (1992) Chemical defenses of marine molluscs. In: Paul VJ (ed) Ecological roles for marine natural products. Cornell University Press, Ithaca, p 119-163

Fishlyn DA, Phillips DW (1980) Chemical camouflaging and behavioural defenses against a predatory seastar by three species of gastropods from the surfgrass Phyllospadix community. Biol Bull 158:34-48

Hay ME, Duffy JE, Fenical W (1988a) Seaweed chemical defenses: among-compound and among-herbivore variance. Proc 6th Int Coral Reef Symp 3:43-48

Hay ME, Duffy JE, Paul VJ, Renaud PE, Fenical W (1990) Specialist herbivores reduce their susceptibility to predation by feeding on the chemically defended seaweed Avrainvillea longicaulis. Limnol Oceanogr 35:1734-1743

Hay ME Fenical W, Gustafson K (1987) Chemical defense against diverse coral-reef herbivores. Ecology 68:1581-1591

Hay ME, Paul VJ, Lewis SM, Gustafson K, Trindell RN (1988b) Can tropical seaweeds reduce herbivory by growing at night? Diel patterns of growth, nitrogen content, herbivory. and chemical versus morphological defense. Oecologia 75:233-245

Ireland C. Scheuer PJ (1979) Photosynthetic marine molluscs: in vivo ${ }^{14} \mathrm{C}$ incorporation into metabolites of the sacoglossan Placobranchus ocellatus. Science 205:922-923

Kazlauskas R, Murphy PT, Quinn RJ, Wells RJ (1977) A new class of halogenated lactones from the red alga Delisea fimbriata (Bonnemaisoneaceae). Tetrahedron Lett 1:37-40

Kernan MR, Faulkner DJ (1987) Halichondromide, an antifungal microlide from the sponge Halichondria sp. Tetrahedron Lett 28:2809-2812

Lindquist N, Hay ME (1995) Can small rare prey be chemically defended? The case for marine larvae. Ecology 76:1347-1358

McCombs JD, Blunt JW, Chambers MV, Munro MHG, Robinson WT (1988) Novel 2(5H)-Furanones from the marine alga Delisea elagans (Lamouroux). Tetrahedron 44:1489-1502
Mever KD, Paul VJ (1992) Intraplant variation in secondary metabolite concentration in three species of caulerpa (Chlorophyta: Caulerpales) and its effects on herbivorous fish. Mar Ecol Prog Ser 82:249-257

Paul VJ (1992) Seaweed chemical defences on coral reefs. In Paul VJ (ed) Ecological roles for marine secondary metabolites. Cornell Unıversity Press, Ithaca, p 24-50

Paul VJ, Fenical W (1986) Chemical defense in tropical green algae, order Caulerpales. Mar Ecol Prog Ser 34:157-169

Paul VJ, Fenical W (1987) Naturdi products chemistry and chemical defense in tropical marine algae of the phylum chlorophyta. In: Scheuer P (ed) Bioorganic manne chemistry 1. Springer-Verlag, Berlin, p 1-29

Paul VJ, Pennings SC (1991) Diet-derived chemical defenses in the sea hare Stylocheilus longicauda (Quoy et Gaimard 1824). J exp mar Biol Ecol 151:227-243

Paul VJ, Lindquist N, Fenical W (1990) Chemical defenses of the tropical ascidian Atapozoa sp. and its nudibranch predators Nembrotha spp. Mar Ecol Prog Ser 59:109-118

Paul VJ, van Alstyne KL (1988a) Use of ingested algal diterpenoids by Elysia halimedae Macnae (Opisthobranchia: Ascoglossa) as antipredator defenses. J exp mar Biol Ecol 119:15-29

Paul VJ, van Alstyne KL (1988b) Chemical defence and chemical variation in some tropical Pacific species of Halimeda (Halimedaceae; Chlorophyta). Coral Reefs 6:263-269

Paul VJ, Wylie CR, Sanger HR (1988) Effects of algal chemical defenses toward different coral-reef herbivorous fishes: a preliminary study. Proc 6th Int Coral Reef Symp 3:73-78

Pawlik JR, Kernan MR, Molinski TF, Harper MK, Faulkner DJ (1988) Defensive chemicals of the Spanish dancer nudibranch Hexabranchus sanguineus and its egg ribbons: macrolides derlved from a sponge diet. J exp mar Biol Ecol 119:99-109

Pennings SC (1990) Multiple factors promoting narrow host range in the sea hare, Aplysia californica. Oecologia 82 . $192-200$

Pennings SC (1994) Interspecific variation in chemical defenses in the sea hares (Opisthobranchia: Anaspidea) J exp mar Biol Ecol 180:203-219

Pennings SC, Paul VJ (1993a) Secondary chemistry does not limit the dietary range of the specialist sea hare Stylocheilus longicauda (Quoy et Gaimard 1824). J exp mar Biol Ecol 174:97-113

Pennings SC, Paul VJ (1993b) Sequestration of dietary secondary metabolites by three species of sea hares: location, specificity and dynamics. Mar Biol 117:535-546

Pettus JA, Wing RM, Sims JJ (1977) Marine natural products. XII. Isolation of a family of multihalogenated gammamethylene lactones from the red seaweed Delisea fimbriata. Tetrahedron Lett 1:41-44

Phillips DW, Towers GHN (1982) Chemical ecology of red algal bromophenols. I. Temporal, interpopulational and within-thallus measurements of lanosol levels in Rhodomela larix (Turner) C. Agardh. J exp mar Biol Ecol 58 285-293

Ragan MA, Glombitza KW (1986) Phlorotannins, brown algal polyphenols. Prog phycol Res 4:129-241

Reichelt JL, Borowitzka MA (1984) Antimicrobial activity from marine algae: results of a large-scale screening programme. Hydrobiologia 116/117:158-168

Roesener JA, Scheuer PJ (1986) Ulapualide A and B, extaordinary antitumor macrolides from nudibranch eggmasses. J Am Chem Soc 108:846-847

Rogers CN, Steinberg PD, de Nys R (1995) Factors associated with oligophagy in two species of sea hares (Mollusca Anaspidea). J exp mar Biol Ecol 192:47-73 
Rose AF, Pettus JA, Sims JJ (1977) Marine natural products. XIII. Isolation and synthesis of some halogenated ketones from the red seaweed Delisea fimbriata. Tetrahedron Lett 22:1847-1850

Rowell-Rahier M, Pasteels JM (1992) Third trophic level influences of plant allelochemicals. In: Rosenthal GA, Berenbaum MR (eds) Herbivores: their interactions with secondary plant metabolites. 2: Ecological and evolutionary processes. Harcourt Brace Jovanovich, San Diego, p 243-278

Sokal RR, Rohlf FJ (1981) Biometry, 2nd edn. WH Freeman, San Francisco

Stallard MO, Faulkner DJ (1974) Chemical constituents of the digestive gland of the sea hare Aplysia californica - I. Importance of diet. Comp Biochem Physiol B 49:25-35

Steinberg PD (1992) Geographical variation in the interaction between marine herbivores and brown algal secondary metabolites. In: Paul VJ (ed) Ecological roles for marine secondary metabolites. Cornell University Press, Ithaca, p 51-92

This article was presented by J. Pawlik, Wilmington, North Carolina, USA
Steinberg PD, van Altena I (1992) Tolerance of marine invertebrate herbivores to brown algal phlorotannins in temperate Australasia. Ecol Monogr 62:189-222

Targett NM, Coen LD, Boettcher AA, Tanner CE (1992) Biogeographic comparisons of marine algal polyphenolics: evidence against a latitudinal trend. Oecologia 89:464-470

Thompson JE, Walker RP, Wratten SJ, Faulkner DJ (1982) A chemical defense mechanism for the nudibranch Cadlina luteomarginata. Tetrahedron 38:1865-1873

Tugwell S, Branch GM (1989) Differential polyphenolic distribution among tissues in the kelps Ecklonia maxima, Laminaria pallida and Macrocystis angustifolia in relation to plant-defence theory. J exp mar Biol Ecol 129:219-230

Vardaro RR, Di Marzo V, Crispino A, Cimino G (1991) Cyercenes, novel polypropionate pyrones from the autotomizing Mediterranean mollusc Cyerce cristallina. Tetrahedron 47:5569-5576

Winkler LR (1969) Distribution of organic bromine compounds in Aplysia californica Cooper, 1863. Veliger 11 $268-271$

Manuscript first received: November 7, 1994

Revised version accepted: July 6, 1995 